\title{
Preparation and Characterization of Amphiphilic Poly(ethylene glycol) Graft Copolymers
}

\author{
Hsin-Cheng ChIU, Chun-Hsia Hu* and Chorng-Shyan CHERN ${ }^{*, \dagger}$ \\ Department of Chemical Engineering, National Chung Hsing University, \\ Taichung 402, Taiwan, Republic of China \\ * Department of Chemical Engineering, National Taiwan University of Science and Technology, \\ Taipei 106, Taiwan, Republic of China
}

(Received December 10, 1998)

\begin{abstract}
Amphiphilic graft copolymers of alkyl methacrylates, methoxy poly(ethylene glycol) (PEG) acrylate, and acrylic acid were synthesized by free radical polymerization. PEG graft copolymers with respect to structure, composition, and average molecular weight were characterized by FT-IR, ${ }^{1} \mathrm{H}$ NMR, and GPC. The critical micelle concentration and molar mass of the polymeric micelles were determined by fluorescence spectroscopy using pyrene as the fluorescence probe and static laser light scattering, respectively. The formation of polymeric micelles was influenced by the balance of hydrophobicity and hydrophilicity and other factors such as molecular weight of the copolymer products. The molar mass of polymeric micelles increased with mole content of hydrophobic comonomers. Loading capacity and weight average partition coefficient for the pyrene molecules into polymeric micelles were estimated via fluorescence quenching by $\mathrm{Cu}^{2+}$. Fluorescence quenching studies of pyrene indicated that a loose structure of micelles was formed from the graft copolymer containing high content of hydrophilic monomethoxy poly(ethylene glycol) (mPEG) and acrylic acid.

KEY WORDS Amphiphilic Copolymers / Polymeric Micelles / Poly(ethylene glycol) / Fluorescence Emission / Quenching /
\end{abstract}

Amphiphilic poly(ethylene glycol) (PEG) graft copolymers have applications in several fields. PEG graft copolymers may accumulate at interfaces and can be used as stabilizers for emulsion. ${ }^{1}$ Multiple attachments along the polymer chain at interfaces enable polymeric surfactants at low concentration to retain the steric stabilizing effect for emulsion and dispersion. Applications of amphiphilic PEG copolymers on modification of biomedical polymer surfaces for reducing protein adsorption and increasing their biocompatibility have been extensively reported. ${ }^{2,3}$ The formation of polymeric micelles in aqueous solution also offers an appropriate vehicle as a controlled drug delivery system for hydrophobic bioactive agents. ${ }^{4-7}$ Interest in applications of amphiphilic PEG-containing copolymers for modification of biopolymer surfaces and/or design of drug delivery systems stems mainly from the effective exclusion properties of PEG in aqueous solution (i.e., high protein repulsion and low cell adhesion). ${ }^{8,9}$

Two main synthetic routes have been frequently used for preparing amphiphilic PEG graft copolymers. The synthesis of polymeric precursors followed by PEG conjugation via polymeric analogous reaction usually requires the incorporation of comonomers containing reactive functional groups for subsequent PEG conjugation. Wesslen and Wesslen prepared amphiphilic combshaped copolymers by the polymerization of 2-ethylhexyl acrylate with glycidyl methacrylate, followed by transesterification of monomethoxy poly(ethylene glycol) (mPEG). ${ }^{1}$ Derand and Wesslen conjugated mPEG onto the copolymers of styrene and maleic anhydride for preparation of anionic comb-shaped PEG graft copolymers. ${ }^{10}$ Twaik et al. and Thierry and Skoulis synthesized PEG graft copolymers in a similar manner. ${ }^{11,12}$ Jannasch et al. initiated the grafting polymerization of ethylene

\footnotetext{
† To whom correspondence should be addressed.
}

oxide on the ionized poly(styrene-co-acrylamide) backbone by potassium $t$-butoxide or potassium naphthalene. ${ }^{13}$ The second synthetic route employed copolymerization of vinyl monomers with PEG macromonomers. For example, Lee et al. prepared PEG graft copolymers by copolymerization of mPEG methacrylate with alkyl methacrylates. ${ }^{2}$ The reactivity of various PEG macromonomers in free radical copolymerization with styrene was investigated by Ito et al. ${ }^{14}$

Physicochemical properties of amphiphiplic copolymers in aqueous solution have attracted attention. The formation of polymeric micelles from amphiphilic graft copolymers in aqueous solution was attributed to aggregation of hydrophobic side chains of graft copolymers. Water-soluble copolymers containing hydrophilic and hydrophobic moieties in the side chains are sometimes referred to as "polysoaps". ${ }^{15,16}$ The mechanism of formation of polymeric micelles from polysoaps has been reported by several investigators. ${ }^{17-20}$ Barbieri and Strauss reported that polymeric micelles are formed as a consequence of intermolecular aggregation of hydrophobic side chains of polysoaps. ${ }^{17}$ Chen and Thomas, however, attribute the formation of polymeric micelles to aggregation from all hydrophobic side chains of a given macromolecule. ${ }^{19}$ The mechanism of intermolecular micellization was recently supported by measurement of fluorescence quenching and neutron scattering. ${ }^{21}$ Konak et al. observed the formation of multimolecular micelles from amphiphilic PEG graft copolymers. ${ }^{15}$ In our previous report, ${ }^{22}$ PEG graft copolymers were synthesized by first preparing polymeric precursors containing reactive functional groups derived from acryloyl chloride. This was followed by esterification of the precursors with $\mathrm{mPEG}$ and methanol. The molar masses of polymeric micelles formed via aggregation of these copolymer species in water were determined by static light scattering and the influence 
of the content of hydrophobic comonomers on the molecular number of aggregation per micelle was investigated.

This study used the macromonomer approach to prepare a series of amphiphilic graft copolymers comprising monomeric units of alkyl methacrylate (stearyl methacrylate or lauryl methacrylate), mPEG acrylate, and acrylic acid (or butyl acrylate or 2-hydroxyethyl methacrylate). The structures of PEG graft copolymers were characterized by FT-IR and ${ }^{1} \mathrm{H}$ NMR. The critical micelle concentrations of these amphiphilic graft copolymers were evaluated by fluorescence spectroscopy using pyrene as the fluorescence probe. The molar masses of the polymeric micelles were determined by static light scattering. The structures of micelles were studied by quenching of the fluorescence intensity of pyrene.

\section{EXPERIMENTAL}

\section{Materials}

mPEG $\left(M_{w} 2000\right.$ and $\left.750 \mathrm{~g} \mathrm{~mol}^{-1}\right)$, acrylic acid (AA), acryloyl chloride, 2-hydroxyethyl methacrylate (HEMA), butyl acrylate (BA), 2,2'-azobisisobutyronitrile (AIBN), pyrene and triethylamine were purchased from Aldrich. Acryloyl chloride (96\%) was distilled under reduced pressure before use. The reagent $\mathrm{mPEG}$ was dried in vacuo for $24 \mathrm{~h}$. Triethylamine was distilled from $\mathrm{Na}$ before use. Stearyl methacrylate (SMA) and lauryl methacrylate (LMA) were obtained from Mitsubishi Rayon Company, Japan. SMA and AIBN were purified by recrystallization from dry methanol before use. All other chemicals were analytic grade and used as received.

\section{Synthesis}

The macromonomer mPEG acrylate was prepared by acylation of $\mathrm{mPEG}\left(M_{w} 2000 \mathrm{~g} \mathrm{~mol}^{-1}\right)$ with acryloyl chloride according to the following procedure. ${ }^{23}$ To a solution of mPEG $(8.5 \mathrm{mmol})$ and triethylamine $(73$ $\mathrm{mmol})$ in toluene $(100 \mathrm{~mL})$ under nitrogen at room temperature, $23 \mathrm{mmol}$ acryloyl chloride were added with a syringe. After stirring for $6 \mathrm{~h}$, the hydrochloride salt was removed by filtration and the solution was concentrated. The product was collected by precipitation in $n$-hexane twice and dried in vacuo. Acylation of mPEG $\left(M_{w} 750 \mathrm{~g} \mathrm{~mol}^{-1}\right)$ with acryloyl chloride was performed in a similar manner.

The mPEG-grafted copolymers were prepared by the free radical polymerization of PEG acrylate, SMA (or LMA), and AA (or HEMA or BA) using AIBN as the initiator (see Table I for details). Polymerization was carried out in toluene solution containing $12 \mathrm{wt} \%$ of monomers and $0.5 \mathrm{wt} \%$ of $\mathrm{AIBN}$ at $70^{\circ} \mathrm{C}$ with stirring under $\mathrm{N}_{2}$ for $24 \mathrm{~h}$. Preparation of copolymer $\mathrm{G}$ was carried out in a semi-batch manner. The monomer BA was equally added to the polymerization solution every $10 \mathrm{~min}$ through a period of $60 \mathrm{~min}$. After polymerization, the volume of polymer solution was reduced to $c a$. $30 \%$ using a rotary evaporator under reduced pressure. The polymer was precipitated from $n$-hexane three times and dried in vacuo. The crude product was dissolved in D.I. water and subjected to ultrafiltration (Amicon, membrane YM-10, MWCO 10,000) for further purification. The PEG graft copolymer product was collected by lyophilization. Yields for this series of polymerizations calculated from the ratios of the weights of copolymer products to monomers ranged from $c a$. $29 \%$ to $68 \%$. Observed deviation in yield was probably related to various molar ratios of hydrophilic and hydrophobic monomers used in the synthesis of the graft copolymers.

\section{Structural Characterization of Copolymers}

The structure of PEG acrylate was characterized by Fourier transform infrared spectroscopy (FT-IR) (Jasco model 700) and ${ }^{1} \mathrm{H}$ nuclear magnetic resonance $\left({ }^{1} \mathrm{H}\right.$ NMR) spectroscopy (Varian Gemin 2000, $200 \mathrm{MHz}$ ). FT-IR spectra showing typical peaks for $\mathrm{C}=\mathrm{C}$ at $c a$. $1605-1635 \mathrm{~cm}^{-1}, \mathrm{C}=\mathrm{O}$ at $1717 \mathrm{~cm}^{-1}$ and $\mathrm{C}-\mathrm{O}-\mathrm{C}$ at $1109 \mathrm{~cm}^{-1}$ along with the disappearance of peaks at 1786 and $717 \mathrm{~cm}^{-1}$ attributed to $\mathrm{C}=\mathrm{O}(\mathrm{Cl})$ and $-\mathrm{Cl}$, respectively, were in agreement with their structural characteristics. The NMR spectra also show typical signals attributed to acrylate ( $c a$. 5-6 ppm), the methoxy group $\left(-\mathrm{OCH}_{3}\right)(3.3 \mathrm{ppm})$, and $-\mathrm{CH}_{2} \mathrm{CH}_{2} \mathrm{O}-$ of mPEG (3.6 ppm). The samples were run in $\mathrm{CDCl}_{3}$ at ambient temperature.

The number and weight average molecular weights of PEG graft copolymers were estimated by gel permeation chromatography (GPC) (Jordi-Gel DVB column, 10 ${ }^{6}$, $10^{4}$, and $10^{3} \mathrm{~A}$ ) using tetrahydrofuran (THF) as the eluent and polystyrene (Polysciences) as the standard for molecular weight calibration. The purity of the copolymer products was checked by GPC and complete removal of unreacted monomers was confirmed. FT-IR spectra show the structural characteristics of the PEG graft copolymers. The compositions of amphiphilic PEG-grafted copolymers were evaluated from ${ }^{1} \mathrm{H}$ NMR spectra by comparing characteristic integrated signals quantitatively. The spectra were taken at ambient temperature in $\mathrm{CDCl}_{3}$ containing $1 \%(\mathrm{v} / \mathrm{v})$ of tetramethylsilane (TMS) as the internal standard. Owing to overlap in resonance signals for BA and LMA, the composition of copolymer $G$ was estimated based on the contribution of each monomer to integrated peaks ranging from 3.2 to $4.5 \mathrm{ppm}, 1.0$ to $2.7 \mathrm{ppm}$, and 0.8 to $0.9 \mathrm{ppm}$.

\section{Fluorescence Measurements}

Fluorescence spectra of pyrene in the aqueous solutions of PEG graft copolymers were obtained using a spectrofluorimeter (Shimadzu, RF-5301PC) at 300$500 \mathrm{~nm}$. The excitation of pyrene was carried out at $336 \mathrm{~nm}$. The emission spectra of pyrene (in all cases, the concentration of pyrene is $6.0 \times 10^{-7} \mathrm{M}$, i.e., solubility of pyrene in water) in aqueous solution with various concentrations of copolymer were recorded. The ratio of the intensity of the third and first vibronic peaks $\left(I_{3} / I_{1}\right)$ as a function of copolymer concentration was calculated. ${ }^{24,25}$

The quenching of fluorescence emission of pyrene in aqueous solution of copolymer was performed by addition of $\mathrm{Cu}^{2+} .26$ The ratio of the intensity of the third vibronic peaks obtained from the pyrene/copolymer solution in the presence of $\mathrm{Cu}^{2+}$ to that obtained from the solution without $\mathrm{Cu}^{2+}\left(I_{3} / I_{3,0}\right)$ was evaluated. 
Table 1. Molar ratios of monomers used in the preparation of PEG graft copolymers ${ }^{\mathbf{a}, \mathbf{b}}$

\begin{tabular}{|c|c|c|c|c|c|c|c|}
\hline Polymer ID & $\mathrm{mPEG}_{2000}$ acrylate & $\mathrm{mPEG}_{750}$ acrylate & $\mathrm{AA}$ & SMA & LMA & HEMA & $\mathrm{BA}$ \\
\hline A & 1.0 & & 3.0 & 0.75 & & & \\
\hline B & 1.0 & & 3.0 & & 0.75 & & \\
\hline C & & 1.0 & 3.0 & 0.75 & & & \\
\hline D & 1.0 & & 2.0 & & 0.50 & & \\
\hline $\mathrm{E}$ & 1.0 & & 1.3 & & 0.50 & & \\
\hline F & 1.0 & & & & 0.75 & 3.0 & \\
\hline G & 1.0 & & & & 0.75 & & 3.0 \\
\hline
\end{tabular}

${ }^{\mathrm{a}}$ Concentration of total monomers in toluene, $12 \mathrm{wt} \% . \quad{ }^{\mathrm{b}}$ Concentration of AIBN in toluene, $0.5 \mathrm{wt} \%$.

\section{Measurements of Molar Masses of Micelles}

The molar masses of polymeric micelles $\left(M_{w}\right)$ were characterized by static light scattering (Otsuka, DLS7000) equipped with a $10 \mathrm{mV} \mathrm{He}-\mathrm{Ne}$ laser at a wavelength $(\lambda)$ of $632.8 \mathrm{~nm}$. The scattering angles $(\theta)$ ranged from $30^{\circ}$ to $150^{\circ}$. All light scattering experiments were performed at $25^{\circ} \mathrm{C}$. The molar masses of micelles prepared by various amphiphilic copolymers were estimated by measuring the excess Rayleigh ratio $\left(R_{\theta}\right)$ as,

$$
\begin{aligned}
K(C-C M C) / R_{\theta}= & 1 / M_{w}+\left(1 / M_{w}\right)\left(16 \pi^{2} / 3 \lambda^{2}\right) S^{2} \sin ^{2}(\theta / 2) \\
& +2 A_{2}(C-C M C)
\end{aligned}
$$

where $K$ is the optical constant with the incorporated refractive index, $S^{2} z$-average radius, $C$ polymer concentration in $\mathrm{g} \mathrm{mL}^{-1}$, and $A_{2}$ second viral coefficient obtained from a Zimm plot which extrapolates $\theta$ and $C$ to the limits. CMC (critical micelle concentration) for PEG graft copolymers was obtained from fluorescence measurement. The refractive index increment $(\mathrm{d} n / \mathrm{d} c)$ was obtained by a differential refractometer (Otsuka, DRM 1201) with copolymers dissolved in THF at $633 \mathrm{~nm}$ at $25^{\circ} \mathrm{C}$.

\section{RESULTS AND DISCUSSION}

Amphiphilic copolymers comprising monomeric units of mPEG acrylate, SMA (or LMA), and AA (or HEMA or BA) were synthesized by free radical polymerization. The macromonomer, mPEG acrylate, was prepared by acylation of mPEG $\left(M_{w} 2000\right.$ and $\left.750 \mathrm{~g} \mathrm{~mol}^{-1}\right)$ with acryloyl chloride and the structure was confirmed by FT-IR and ${ }^{1} \mathrm{H}$ NMR. Table I shows monomer compositions for the preparation of seven amphiphilic PEG-grafted copolymers. The molecular structure of copolymer A, which comprises PEG acrylate, SMA, and AA is shown in Figure 1. The purity of the graft copolymers characterized by GPC indicated that, after repeated precipitation from $n$-hexane and ultrafiltration, unreacted monomers with low molecular weight, PEG acrylate macromonomer, and oligomers were thoroughly removed. Characterization of these PEG-grafted copolymers by FT-IR was in agreement with the structures. Figure 2 shows the FT-IR spectrum for copolymer A. This spectrum shows bands at $1109 \mathrm{~cm}^{-1}$ (asymmetrical stretching of C-O-C), at 2914 and $2844 \mathrm{~cm}^{-1}$ (asymmetrical and symmetrical stretching bands of methylene and methyl groups) and absorption at 3400 and 1717 $\mathrm{cm}^{-1}$ for the carboxyl group. Average molecular weight and polydispersity of PEG graft copolymers were estimated by GPC using polystyrene as the calibration

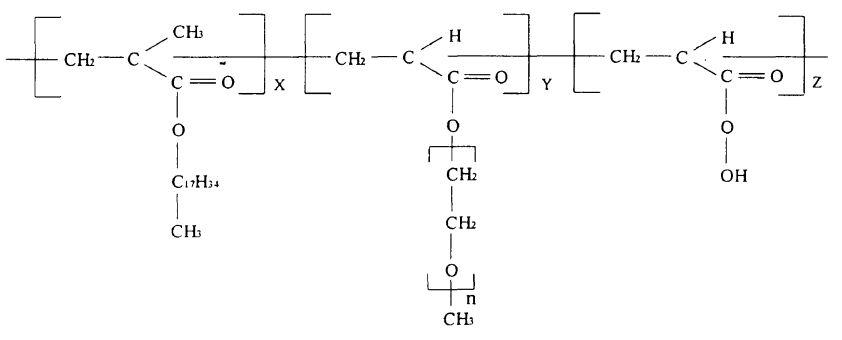

Figure 1. Molecular structure of copolymer A.

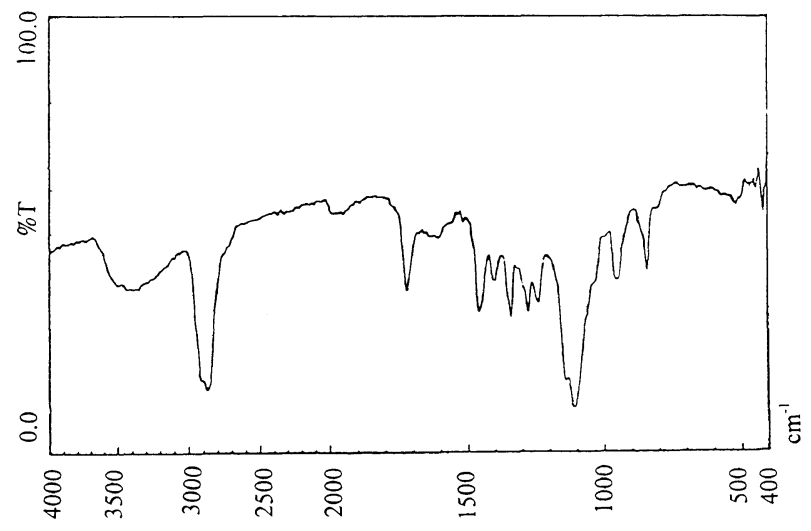

Figure 2. FT-IR spectrum of copolymer A.

Table II. Characterization data for amphiphilic

\begin{tabular}{|c|c|c|c|c|}
\hline \multirow{2}{*}{$\begin{array}{l}\text { Polymer } \\
\text { ID }\end{array}$} & \multirow{2}{*}{ Monomers } & \multirow{2}{*}{$\begin{array}{l}\text { Composition } \\
\text { ratio }^{\mathrm{a}}\end{array}$} & \multirow{2}{*}{$\frac{\mathrm{MW}^{\mathrm{b}}}{\mathrm{g} \mathrm{mol}^{-1}}$} & \multirow{2}{*}{$\begin{array}{c}\text { Poly- } \\
\text { dispersity }^{\mathrm{b}}\end{array}$} \\
\hline & & & & \\
\hline $\mathrm{A}$ & PEG(2054)/AA/SMA & $1.0 / 16.0 / 1.0$ & 19350 & 2.5 \\
\hline B & PEG(2054)/AA/LMA & $1.0 / 8.9 / 0.9$ & 24400 & 2.6 \\
\hline $\mathrm{C}$ & PEG(804)/AA/SMA & $1.0 / 4.4 / 0.9$ & 23080 & 2.4 \\
\hline $\mathrm{D}$ & PEG(2054)/AA/LMA & $1.0 / 1.2 / 0.6$ & 34740 & 2.3 \\
\hline $\mathrm{E}$ & PEG(2054)/AA/LMA & $1.0 / 1.9 / 0.5$ & 41440 & 2.8 \\
\hline $\mathrm{F}$ & PEG(2054)/HEMA/LMA & $1 / 3.7 / 1.0$ & 43270 & 2.7 \\
\hline G & PEG(2054)/BA/LMA & $1 / 2.2 / 1.0$ & 41350 & 4.0 \\
\hline
\end{tabular}
PEG graft copolymers

${ }^{a}$ Determined by ${ }^{1} \mathrm{H}$ NMR. $\quad{ }^{\text {b }}$ Determined by GPC using polystyrene as the calibration standard.

standard. The calibration established from linear polystyrene standards may lead to smaller average molecular weights of the PEG-grafted copolymers. Weight-average molecular weight data ranged from 20000 to 43000 $\mathrm{g} \mathrm{mol}^{-1}$ (Table II). Molecular weight distribution (polydispersity) was quite close except for copolymer $\mathrm{G}$. The relatively large polydispersity for copolymer $G$ was probably due to the semi-batch process used for preparing this copolymer, leading to a rather different termination rate during the addition of BA monomer in 


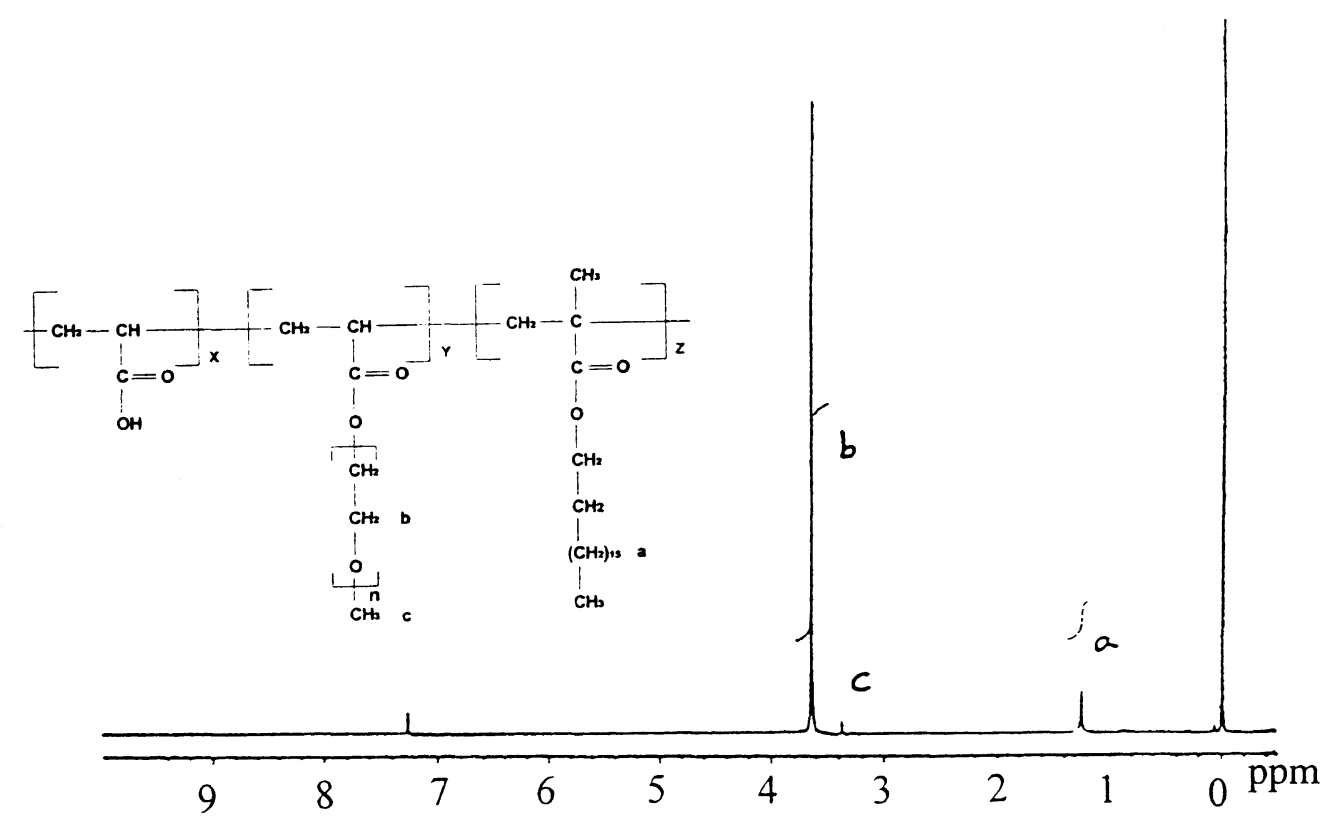

Figure 3. ${ }^{1} \mathrm{H}$ NMR spectrum of copolymer A.

comparison with the batch process. Ultrafiltration of PEG graft copolymers using a membrane of MWCO 10000 gave rise to higher average molecular weights.

Quantitative determination of the compositions of PEG-grafted copolymers was performed using the ${ }^{1} \mathrm{H}$ NMR spectra (Table II). For calibration of the mole contents of mPEG acrylate and SMA (or LMA) in the copolymer products, the ${ }^{1} \mathrm{H}$ NMR spectra of each monomer (including mPEG, SMA, and LMA) with two different concentrations were also obtained quantitatively under exactly the same conditions as for the graft copolymers. For copolymers comprising mPEG acrylate, SMA (or LMA), and AA (or HEMA), integrated signals attributed to $-\mathrm{CH}_{2} \mathrm{CH}_{2} \mathrm{O}-$ of $\mathrm{mPEG}$ $(\delta=3.65 \mathrm{ppm})$ and $-\mathrm{CH}_{2} \mathrm{CH}_{2}-$ of SMA (or LMA) $(\delta=1.08 \mathrm{ppm})$ were compared with the corresponding integrated signals of NMR spectra from $M P E G$ and SMA (or LMA) monomers and mole content evaluated. The mole content of the third comonomer (AA or HEMA) was obtained by mass balance. Figure 3 shows the NMR spectrum of copolymer A. Owing to overlapping signals from BA and LMA, the composition of copolymer $\mathrm{G}$ was estimated according to the method of Oliveira and Gomes. ${ }^{28}$ The integrated area obtained from the signals between 3.2 and $4.5 \mathrm{ppm}$ was assigned to $-\mathrm{C}(=\mathrm{O})-\mathrm{O}-\mathrm{CH}_{2}-$ of LMA, $-\mathrm{C}(=\mathrm{O})-\mathrm{O}-\mathrm{CH}_{2}-$ of $\mathrm{BA}$, and $-\mathrm{CH}_{2} \mathrm{CH}_{2} \mathrm{O}$ - and methyl end groups of mPEG acrylate. The area between 1.0 to $2.7 \mathrm{ppm}$ was assigned to the hydrogen atoms (including the methyl groups) of the polymeric backbone, the rest of methylene groups of LMA and BA, and the area between 0.8 and $0.9 \mathrm{ppm}$ to the methyl end groups of LMA and BA.

The critical micelle concentrations (CMC) of amphiphilic PEG graft copolymers were determined by fluorescence spectroscopy using pyrene as the fluorescence probe. Owing to hydrophobicity, pyrene molecules preferentially partition into the hydrophobic microdomain in aqueous medium. The emission spectra of pyrene generally show vibronic peaks. The ratio of the intensity of the third and first peaks $\left(I_{3} / I_{1}\right)$ is frequently utilized

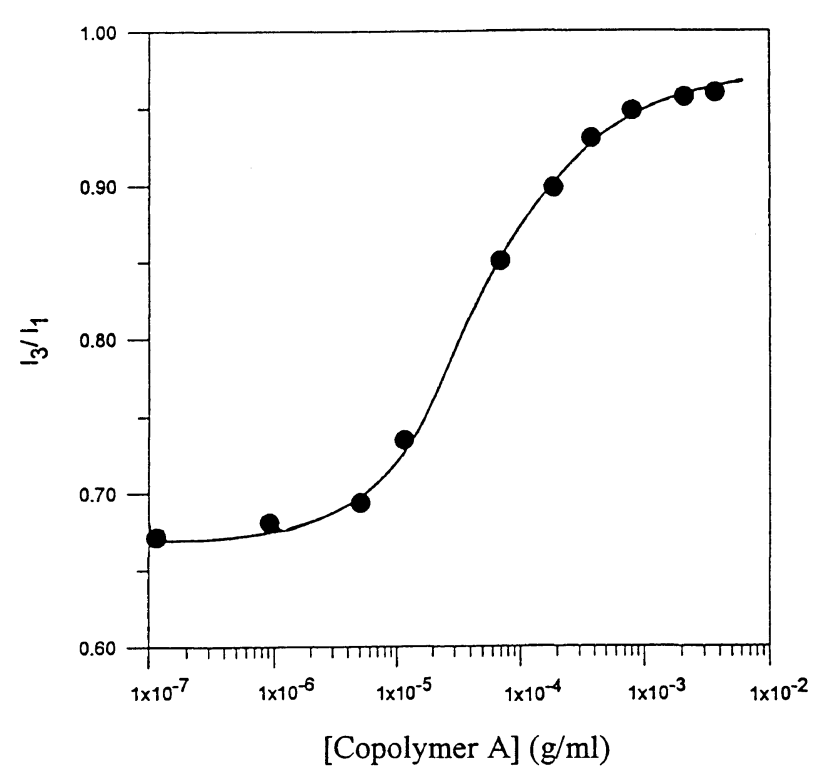

Figure 4. Variation in $I_{3} / I_{1}$ as a function of the concentration of copolymer A. Concentration of pyrene, $6.0 \times 10^{-7} \mathrm{M}$.

for detection of the conformational change of polymers in aqueous solutions. ${ }^{24,29} I_{3} / I_{1}$ is close to 0.59 for pyrene in water and increases to $c a$. 1.1 in hydrophobic environment. ${ }^{25}$ Therefore, change of $I_{3} / I_{1}$ may serve as a measure of alteration in the polarity of the pyrene microenvironment. In this study, the emission spectra of pyrene were recorded and $I_{3} / I_{1}$ as a function of polymer concentration in D.I. water calculated. The concentration of pyrene in water remained at $6.0 \times$ $10^{-7} \mathrm{M}$ to avoid the formation of excimer. CMC of graft copolymers was determined from the polymer concentration at which $I_{3} / I_{1}$ essentially reached a plateau level. Figure 4 shows the data of $I_{3} / I_{1}$ as a function of the concentration of copolymer $\mathrm{A}$ in water ([Copolymer A]). Figure 4 clearly demonstrates that, with increasing [Copolymer A], $I_{3} / I_{1}$ at first increases slowly and then rises rapidly with the formation of polymeric micelles. 
Table III. Micellar properties of amphiphilic PEG graft copolymers

\begin{tabular}{|c|c|c|c|c|}
\hline \multirow{2}{*}{ Polymer ID } & \multirow{2}{*}{$\frac{\mathrm{CMC}}{\mathrm{g} \mathrm{mL}^{-1}}$} & \multirow{2}{*}{$\frac{M_{W} \text { of micelles }}{\mathrm{a}}$} & \multirow{2}{*}{$N_{\text {agg }}$} & \multirow{2}{*}{$R_{\mathrm{c}} / \mathrm{nm}^{\mathrm{b}}$} \\
\hline & & & & \\
\hline A & $2.5 \times 10^{-4}$ & $3.9 \times 10^{7}$ & 2030 & 12.0 \\
\hline B & $6.5 \times 10^{-4}$ & $1.7 \times 10^{7}$ & 870 & 9.1 \\
\hline $\mathrm{C}$ & $1.5 \times 10^{-4}$ & $5.4 \times 10^{7}$ & 2340 & 17.4 \\
\hline $\mathrm{D}$ & $2.0 \times 10^{-4}$ & $1.9 \times 10^{7}$ & 550 & 8.3 \\
\hline $\mathrm{E}$ & $1.1 \times 10^{-3}$ & $0.9 \times 10^{7}$ & 220 & 6.1 \\
\hline $\mathrm{F}$ & $6.0 \times 10^{-4}$ & $2.4 \times 10^{7}$ & 550 & 10.0 \\
\hline G & $1.0 \times 10^{-4}$ & $1.5 \times 10^{8}$ & 3660 & 24.6 \\
\hline
\end{tabular}

${ }^{a}$ Calculation based on static light scattering measurement. $\quad{ }^{\mathrm{b}} \mathrm{Calcu}-$ lation based on eq 3 .

Stable hydrophobic cores were created at $2.5 \times 10^{-4}$ $\mathrm{g} \mathrm{mL}^{-1}$ (CMC) for copolymer $\mathrm{A}$ as the ratio $I_{3} / I_{1}$ reached 0.95 . $I_{3} / I_{1}$ for amphiphilic PEG graft copolymers at high concentrations ranged from 0.89 to 1.05 , whereas $I_{3} / I_{1}$ reached 0.88 in aqueous solution of sodium lauryl sulfate. ${ }^{25}$ Kown et al. also reported that formation of micelles from block copolymers of PEG with poly $(\beta$ benzyl L-aspartate) in aqueous solution enhanced $I_{3} / I_{1}$ to 0.7 for pyrene. ${ }^{30}$ The increase of $I_{3} / I_{1}$ observed in this study indicated the formation of a hydrophobic microenvironment for pyrene at elevated concentrations of copolymers in water as a result of the incorporation of SMA or LMA.

CMC data thus obtained for the PEG graft copolymers are summerized in Table III. Copolymer A exhibited lower CMC $\left(2.5 \times 10^{-4} \mathrm{~g} \mathrm{~mL}^{-1}\right)$ than copolymer B because of the more hydrophobic nature of SMA than LMA. A previous paper points out that CMC is influenced by hydrophobic/hydrophilic nature and molecular weight of the amphiphilic compounds. ${ }^{22}$ Compared to copolymer A, a lower value of CMC $\left(1.5 \times 10^{-4} \mathrm{~g} \mathrm{~mL}^{-1}\right)$ for copolymer $\mathrm{C}$ was primarily a consequence of the lower molecular weight of mPEG $\left(750 \mathrm{~g} \mathrm{~mol}^{-1}\right)$ grafted onto the backbone of copolymer C. For copolymers comprising identical monomeric units, different molar ratios of monomers also gave rise to distinct aggregation behavior in micelle formation. As expected, copolymer D containing a higher content of LMA and lower content of AA formed micelles in aqueous solution at a lower polymer concentration than copolymer $\mathrm{E}$. $\mathrm{CMC}$ for copolymers $\mathrm{B}$ and $\mathrm{E}$ were comparable and this implies that mPEG acrylate may play a more influential role than $\mathrm{AA}$ in regulating the formation of polymeric micelles. This is probably due to the significant excluded volume effect of mPEG. CMC data for copolymers $F$ and $G$ also illustrate the significance of different water solubilities of BA and HEMA. In this study, copolymer $\mathrm{G}$ exhibited the lowest CMC $(1.0 \times$ $\left.10^{-4} \mathrm{~g} \mathrm{~mL}^{-1}\right)$. In addition to the effect of LMA, we attribute this result to the enhanced hydrophobic effect provided by $\mathrm{BA}$ in semi-batch polymerization. It is noteworthy that $\mathrm{CMC}$ for the PEG graft copolymers prepared in this study were larger than those for the PEG graft or block copolymers reported in the literature. ${ }^{22,30}$ $\mathrm{Xu}$ et al. measured the CMC of PEG-poly(styrene) copolymers by fluorescence spectroscopy and found a CMC value of $c a .4 .0 \times 10^{-6} \mathrm{~g} \mathrm{~mL}^{-1} .^{27}$ Kown et al.

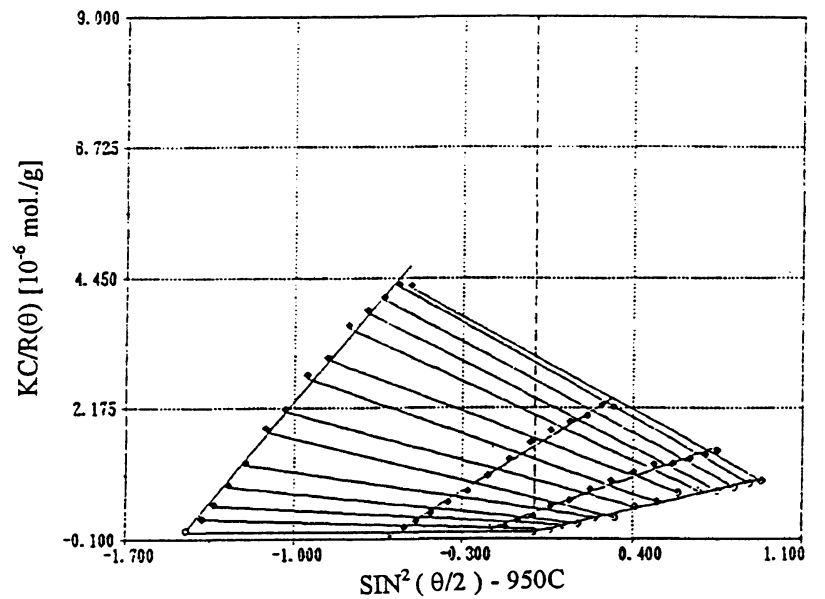

Figure 5. Modified Zimm plots for polymeric micelles made from copolymer $\mathrm{A}$ in water.

reported that the CMC of PEG-poly $(\beta$-benzyl Laspartate) block copolymers ranged from $5.0 \times 10^{-6}$ to $1.0 \times 10^{-5} \mathrm{~g} \mathrm{~mL}^{-1}, 30$ probably due to the high content of hydrophobic comonomers and elevated hydrophobic nature due to block copolymerization. In our previous study, amphiphilic copolymers were prepared from free radical polymerization of methacrylic acid, acryloyl chloride, and SMA, followed by esterification of polymeric precursors with mPEG and methanol. ${ }^{22} \mathrm{CMC}$ ranged from $1.7 \times 10^{-6}$ to $4.0 \times 10^{-6} \mathrm{~g} \mathrm{~mL}^{-1}$. In addition to differences in the hydrophilic/hydrophobic nature of the PEG-grafted copolymers, decreased CMC were also attributed to the high molecular weights ( $c a .100000$ $\mathrm{g} \mathrm{mol}^{-1}$ ) of the PEG-grafted copolymers reported in the previous work. ${ }^{22}$ With increase in the molecular weight of amphiphilic copolymers, the driving force for aggregation of hydrophobic segments is greatly increased.

The molar masses of polymeric micelles in water were estimated by static laser light scattering. Equation 1 developed by $\mathrm{Xu}$ et al. was used to calculate the molar masses of polymeric micelles. ${ }^{27}$ Estimation of molar masses of polymeric micelles according to eq 1 was based on the assumption that unimers and micelles of amphiphilic polymers in the aqueous phase were able to achieve an equilibrium state. The micellar solution was considered micellar particles in the solvent of polymer solution. As a consequence, the concentration of micelles became significant only when polymer concentration was higher than CMC. The second viral coefficient $\left(A_{2}\right)$ was obtained from a Zimm plot with extrapolation of $\theta$ and $C$ to the limits. Figure 5 shows modified Zimm plots for measurement of molar masses of micelles for copolymer A. The molar masses of PEG graft copolymers are shown in Table III. The micellar molecular weights are in the range $1.0 \times 10^{7}-15.0 \times 10^{7}$ $\mathrm{g} \mathrm{mol}^{-1}$. The average molecular numbers of aggregation per micelle $\left(N_{\mathrm{agg}}\right)$ were calculated from the weight average molecular weights of the copolymers. The results are included in Table III. The formation of micelles in aqueous solutions is primarily a consequence of reduction in the interfacial tension between the hydrophobic core of polymeric micelles and water. Therefore, amphiphilic copolymers containing higher content of hydrophobic 


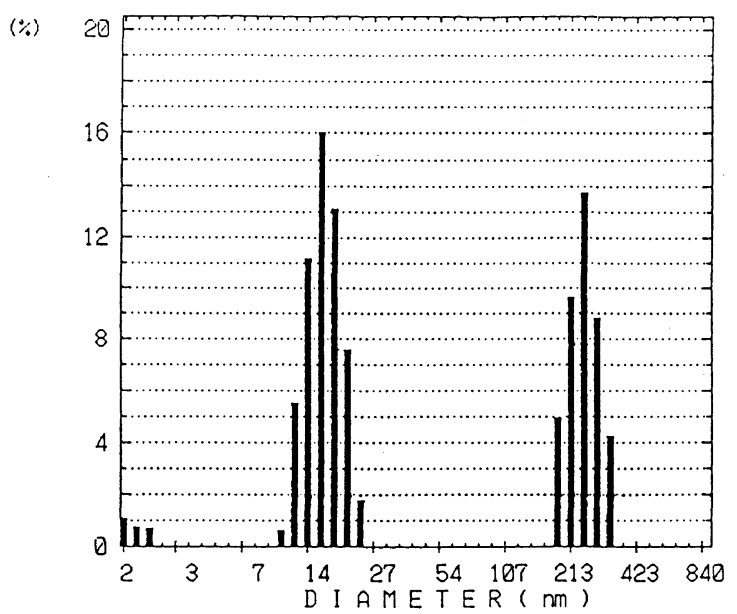

Figure 6. Particle size and size distribution for polymeric micelles made from copolymer $\mathrm{G}$ in water measured by dynamic light scattering.

comonomers exhibited stronger association and less solvation with water. Copolymer $\mathrm{G}$ showed the strongest tendency to aggregate in water owing to the highest content of hydrophobic comonomers (LMA and BA). The relatively lower molecular weight of copolymer $G$ also contributed to the largest value of $N_{\text {agg }}$.

The radius of the hydrophobic core of polymeric micelles $\left(R_{\mathrm{c}}\right)$ was estimated, assuming that the hydrophobic core was assembled by comonomers SMA (or LMA) and BA. The volume of hydrophobic core $\left(V_{\mathrm{c}}\right)$ can be calculated as,

$$
V_{\mathrm{c}}=4 \pi R_{\mathrm{c}}^{3} / 3=\left(M_{w \mathrm{core}} N_{\mathrm{agg}}\right) /\left(\rho_{\text {mix }} N_{\mathrm{A}}\right)
$$

where $M_{w \text { core }}$ is the molecular weight of hydrophobic core, $N_{\mathrm{A}}$ Avogadro's number, and $\rho_{\text {mix }}$ density of the hydrophobic core, obtained based on the weight-average density of the hydrophobic core comprising SMA (or LMA) and BA. To obtain the radius of the hydrophobic core, eq 2 is transformed to,

$$
R_{\mathrm{c}}=\left(3 M_{w \text { core }} N_{\mathrm{agg}} / 4 \pi \rho_{\text {core }} N_{\mathrm{A}}\right)^{1 / 3}
$$

The sizes of polymeric micelles calculated from eq 2 are listed in Table III. As expected, PEG graft copolymers with higher content of hydrophobic comonomers exhibited larger hydrophobic microdomains. The smallest volume of hydrophobic core for copolymer E was due to the high content of MPEG and AA. The average micelle size of copolymer $G$ was evaluated by dynamic light scattering measurement (Otsuka, Photo LPA3000/3100). Polymeric micelle size data calculated by the Stoke-Einstein equation were processed by the histogram method. The average radius of polymeric micelles for copolymer $\mathrm{G}$ was $c a .30 .8 \mathrm{~nm}$, somewhat different from the calculated radius of micelles (the chain length of mPEG plus the radius of hydrophobic core). The discrepancy is perhaps related to the relatively low scattering intensity of large and loose micellar aggregates in dynamic light scattering measurements. Bimodal size distribution was observed (Figure 6). Several investigators in studies on amphiphilic copolymer systems have noted the same. ${ }^{15,22,27,31-33} \mathrm{Xu}$ et al. pointed out that PEG-containing copolymers may aggregate into large and loose micelles and reach thermodynamic equilibrium with micelles of smaller size. ${ }^{27}$ Konak et al.
Table IV. Weight average partition coefficients

\begin{tabular}{|c|c|c|c|c|}
\hline \multirow{2}{*}{$\begin{array}{l}\text { Polymer } \\
\text { ID }\end{array}$} & \multirow{2}{*}{$K_{w}^{a}$} & $\begin{array}{c}\text { Loading } \\
\text { capacity }^{\text {b.c }}\end{array}$ & \multirow{2}{*}{$\begin{array}{c}\begin{array}{c}\text { Loading } \\
\text { capacity }\end{array} \\
\%\end{array}$} & \multirow{2}{*}{$\begin{array}{c}\begin{array}{c}\text { Loading } \\
\text { capacity }\end{array} \\
\%\end{array}$} \\
\hline & & $\%$ & & \\
\hline A & 14000 & 97.25 & 97.56 & 99.37 \\
\hline B & 12300 & 98.77 & 99.50 & 98.06 \\
\hline $\mathrm{C}$ & 37300 & 98.24 & - & - \\
\hline D & 15000 & 96.43 & 97.84 & 97.28 \\
\hline$E$ & 700 & 88.36 & 94.23 & 95.46 \\
\hline $\mathrm{F}$ & 3900 & 95.89 & 99.06 & 94.30 \\
\hline $\mathrm{G}$ & 52000 & 98.11 & 95.60 & 99.12 \\
\hline
\end{tabular}
and loading capacity of pyrene in polymeric micelles

${ }^{a} K_{w}$ and loading capacity were determined by quenching of pyrene fluorescence. ${ }^{\mathrm{b}}$ Concentrations of copolymers were 10 times the corresponding CMC for all loading capacity measurements. ${ }^{c}$ Concentration of pyrene, $1.2 \times 10^{-7} \mathrm{~g} \mathrm{~mL}^{-1}$. ${ }^{\mathrm{d}}$ Concentration of pyrene, $8.1 \times 10^{-8} \mathrm{~g} \mathrm{~mL}^{-1}$. ${ }^{\mathrm{e}}$ Concentration of pyrene, $5.1 \times 10^{-8} \mathrm{~g} \mathrm{~mL}^{-1}$.

attributed the formation of large aggregates from PEG containing copolymers with hydrophobic side chains to random association via hydrophobic interaction of the side chains. ${ }^{15}$ The stable and compact micelles of smaller size were formed as a result of PEG protection of the hydrophobic core from further association or even precipitation.

The partition coefficient of pyrene in aqueous solution of polymeric micelles and loading capacity of pyrene were determined by quenching of pyrene fluorescence in water. In this study, $\mathrm{Cu}^{2+}$ was used as the fluorescence quencher. Owing to the impermeability of $\mathrm{Cu}^{2+}$ into the hydrophobic core of PEG graft copolymers, the extent of fluorescence quenching of pyrene led to estimation of the pyrene concentration in water. The concentration of graft copolymers used in the quenching experiment was 10 times the corresponding CMC. The intensity $\left(I_{3,0}\right.$ and $I_{3}$, respectively) of the third vibronic peak of pyrene before and after the addition of $\mathrm{Cu}^{2+}$ was measured. The loading capacity of pyrene in polymeric micelles was obtained directly from $I_{3} / I_{3,0}$ since this ratio represented the fraction of pyrene buried inside the hydrophobic core of micelles and, therefore, fluorescence was not quenched by $\mathrm{Cu}^{2+}$. The results on the loading capacity of pyrene are shown in Table IV. The loading capacity of pyrene is rather independent of pyrene concentration. High loading capacity (ranging from 95 to $99 \%$ ) for a particular polymeric micelle system at three different pyrene concentrations was observed. A lower loading capacity of pyrene for copolymer $\mathrm{E}$ was due to decreased hydrophobicity.

The weight-average partition coefficient $K_{w}$ for pyrene in the polymeric micelles was evaluated as follows ${ }^{6}$ :

$$
K_{w}=\mathrm{C}_{\mathrm{m}} / C_{\mathrm{s}}
$$

where $C_{\mathrm{m}}$ is the number of moles of pyrene dissolved in one gram of micelles and $C_{\mathrm{s}}$ is the number of moles of pyrene in solution (based on one gram of solvent). The results are shown in Table IV. The partition coefficient increased with hydrophobicity of PEG graft copolymers. $K_{w}$ for copolymer $\mathrm{G}$ was about two orders of magnitude larger than that for copolymer E. The low $K_{w}$ for copolymer $E$ was attributed to the formation of relatively small and loose micellar aggregates. Due to the low 


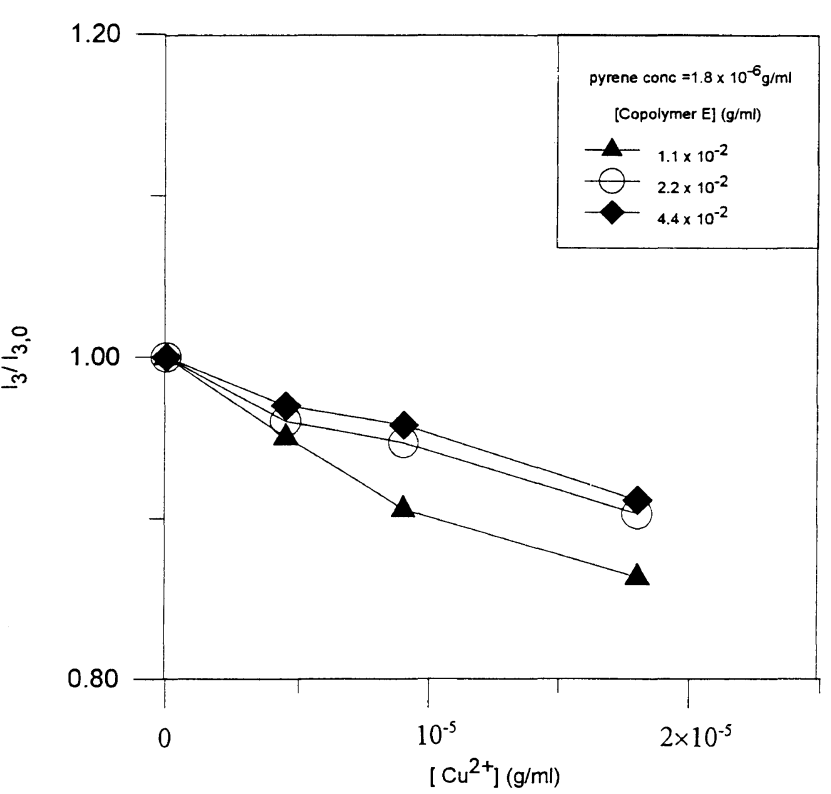

Figure 7. Variation in $I_{3} / I_{3,0}$ as a function of $\mathrm{CuSO}_{4}$ concentration for polymeric micelles made from copolymer $\mathrm{E}$ at various concentrations of copolymer $\mathrm{E}: 0.011 \mathrm{~g} \mathrm{~mL}^{-1}(\mathbf{\Delta}), 0.022 \mathrm{~g} \mathrm{~mL}^{-1}(\mathrm{O})$, and $0.044 \mathrm{~g} \mathrm{~mL}^{-1}(\diamond)$. Concentration of pyrene, $1.8 \times 10^{-6} \mathrm{~g} \mathrm{~mL}^{-1}$.

hydrophobicity of copolymer E, the partition of pyrene into polymeric micelles decreased. The low hydrophobicity resulted in the formation of loose aggregates and, therefore, enhanced the quenching of pyrene fluorescence by $\mathrm{Cu}^{2+}$. To gain better insight into the structure of polymeric micelles prepared by copolymer $\mathrm{E}$, the quenching of the pyrene fluorescence as a function of the concentration of copolymer E ([Copolymer E]) and $\mathrm{Cu}^{2+}\left(\left[\mathrm{Cu}^{2+}\right]\right)$ was studied. From Figure $7, K_{w}$ increased with [Copolymer E] at a pyrene concentration of $1.8 \times 10^{-6} \mathrm{~g} \mathrm{~mL}^{-1}$. It should be noted that quenching increased with $\left[\mathrm{Cu}^{2+}\right]$. In this experiment, $\left[\mathrm{Cu}^{2+}\right]$ was at least two times that of pyrene. This can only be explained by the quenching of pyrene fluorescence inside (or associated with) the micellar aggregates of copolymer $\mathrm{E}$ at larger $\left[\mathrm{Cu}^{2+}\right]$ owing to the liquid-like structure of hydrophobic core made from copolymer E. However, the experimental data regarding the structure of this series of PEG graft copolymers are not conclusive and further research is required.

The authors demonstrated the feasibility of forming polymeric micelles in water by using amphiphilic PEG graft copolymers comprising monomeric units of $\mathrm{mPEG}$ acrylate, SMA (or DMA), and AA (or BA or HEMA). The micellar properties were primarily determined by the hydrophilic/hydrophobic nature of the PEG graft copolymers. Characterization of the amphiphilic copolymers with respect to average molecular weight and micellar properties would suggest potential application in micellar delivery system for hydrophobic therapeutic agents. The cellular uptake of micelles by phagocytes should be reduced and, therefore, the plasma half-life is prolonged due to the repulsion force provided by PEG grafted onto the micelle surface in the aqueous phase as well as the appropriate molecular weight range of these amphiphilic copolymers $\left(\sim 10^{4} \mathrm{~g} \mathrm{~mol}^{-1}\right)$.

\section{REFERENCES}

1. B. Wesslen and K. B. Wesslen, J. Polym. Sci., Part A, Polym. Chem., 27, 3915 (1989).

2. J. H. Lee, P. Kopeckova, J. Kopecek, and J. D. Andrade, Biomaterials, 11, 455 (1992).

3. J. D. Andrade, S. Nagaoka, S. Cooper, T. Okano, and S. W. Kim, ASAIO J., 10, 75 (1987).

4. R. Gref, Y. Minamitake, M. T. Peracchia, V. Trubetskoy, V. Torchilin, and R. Langer, Science, 263, 1600 (1994).

5. J. Vandorpe, E. Schacht, S. Stolnik, M. C. Garnett, M. C. Davies, L. Illum, and S. S. Davis, Biotechnol. Bioeng., 52, 89 (1996)

6. G. S. Kwon, M. Naito, K. Kataoka, M. Yokoyama, Y. Sakurai, and T. Okano, Coll. Surf. B: Biointerfaces, 2, 429 (1994).

7. M. Yokoyama, Crit. Rev. Therap. Drug Carrier Syst., 9, 213 (1992).

8. J. Hermans, J. Chem. Phys., 77, 2193 (1982).

9. A. K. Dolan and S. F. Edwards, Proc. R. Soc. London, 343, 427 (1975).

10. H. Derand and B. Wesslen, J. Polym. Sci., Part A, Polym. Chem., 33, 3571 (1995).

11. M. Twaik, M. Tahan, and A. Zilkha, J. Polym. Sci., Part A, Polym. Chem., A7, 2469 (1969).

12. A. Thierry and A. Skoulios, Makromol. Chem., 177, 319 (1977).

13. P. Jannasch and B. Wesslen, J. Polym. Sci., Part A, Polym. Chem., 31, 1519 (1993).

14. K. Ito, H. Tsuchida, A. Hayashi, T. Kitano, E. Yamada, and T. Matsumoto, Polym. J., 17, 827 (1985).

15. C. Konak, Z. Tuzar, P. Kopeckova, J. D. Andrade, and J. Kopecek, Coliect. Czech. Chem. Commun., 60, 1971 (1995).

16. U. P. Strauss and E. G. Jackson, J. Polym. Sci., 5, 649 (1951).

17. B. W. Barbieri and U. P. Strauss, Macromolecules, 18, 411 (1985).

18. K. Nagai and H. G. Elias, Macromol. Chem., 188, 1095 (1987).

19. D. Y. Chen and J. K. Thomas, Macromolecules, 24, 2212 (1991)

20. E. Mamad and S. Qutubuddin, Macromolecules, 23, 4185(1990).

21. V. S. Zdanowicz and U. P. Strauss, Macromolecules, 26, 4770 (1993).

22. H. C. Chiu, C. S. Chern, C. K. Lee, and H. F. Chang, Polymer, 39, 1609 (1998)

23. V. Fulcrand, R. Jacquier, R. Lazaro, and P. Viallefont, Tetrahedron, 46, 3909 (1990).

24. W. Binana-Limbele and R. Zana, Macromolecules, 20, 1331 (1987).

25. K. Kalyanasundaram and J. K. Thomas, J. Am. Chem. Soc., 99, 2039 (1977)

26. T. Cao, P. Munk, C. Ramireddy, Z. Tuzar, and S. E. Webber, Macromolecules, 24, 6300 (1991)

27. R. Xu, M. A. Winnik, F. R. Hallett, G. Riess, and M. D. Croucher, Macromolecules, 24, 87 (1991).

28. C. M. F. Oliveira and A. S. Gomes, Polym. Bull., 22, 401 (1989).

29. T. S. Chen and J. K. Thomas, J. Polym. Sci., Part A, Polym. Chem., 17, 1103 (1979).

30. G. Kwon, M. Naito, M. Yokoyama, T. Okano, Y. Sakurai, and K. Kataoka, Langmuir, 9, 945 (1993).

31. C. Konak, P. Kopeckova, and J. Kopecek, Macromolecules, 25, 5451 (1992).

32. C. Konak, P. Kopeckova, and J. Kopecek, J. Colloid. Interface Sci., 168, 235 (1994).

33. H. Ringsdorf, J. Simon, and F. M. Winnik, Macromolecules, 25, 5353 (1991). 